\title{
Markers of early disease and prognosis in COPD
}

\author{
Morten Dahl \\ Børge G Nordestgaard \\ Department of Clinical Biochemistry, \\ Herlev Hospital, Copenhagen \\ University Hospital, Faculty of Health \\ Sciences, University of Copenhagen, \\ Copenhagen, Denmark
}

\begin{abstract}
COPD is a complex disease with multiple pathological components, which we unfortunately tend to ignore when spirometry is used as the only method to evaluate the disorder. Additional measures are needed to allow a more complete and clinically relevant assessment of COPD. The earliest potential risk factors of disease in COPD are variations in the genetic background. Genetic variations are present from conception and can determine lifelong changes in enzyme activities and protein concentrations. In contrast, measurements in blood, sputum, exhaled breath, broncho-alveolar lavage, and lung biopsies may vary substantially over time. This review explores potential markers of early disease and prognosis in COPD by examining genetic markers in the $\alpha_{1}$-antitrypsin, cystic fibrosis transmembrane conductance regulator (CFTR), and MBL-2 genes, and by examining the biochemical markers fibrinogen and C-reactive protein (CRP), which correlate with degree of pulmonary inflammation during stable conditions of COPD. Chronic lung inflammation appears to contribute to the pathogenesis of COPD, and markers of this process have promising predictive value in COPD. To implement markers for COPD in clinical practice, besides those already established for the $\alpha_{1}$-antitrypsin gene, further research and validation studies are needed.
\end{abstract}

Keywords: chronic obstructive pulmonary disease, biomarker, pathogenesis, prognosis, genetics

\section{Introduction}

Chronic obstructive pulmonary disease is defined as a disease state characterized by airflow limitation that is not fully reversible; the airflow limitation is usually both progressive and associated with an abnormal inflammatory response of the lungs to noxious particles or gases. ${ }^{1}$ According to the WHO Global Burden of Disease Study, COPD is the fifth leading cause of death worldwide. ${ }^{2}$ Projections from the WHO predict that COPD will continue to increase in the years to come, challenging the health services in countries where cigarette smoking is prevalent. Consequently, we need to improve the diagnostic and therapeutical tools against COPD.

COPD is a complex disease with multiple pathological components, ${ }^{3-6}$ which we unfortunately tend to ignore when spirometry is used as the only method to evaluate the disorder. Additional measures are needed to allow a more complete and clinically relevant assessment of COPD. ${ }^{7-9}$ This may enable better phenotyping of different types of the disease and help improve the evaluation of disease activity and efficacy of therapy. The earliest potential risk factors of disease in COPD are variations in the genetic background. Genetic variations are present from conception and can determine lifelong changes in enzyme activities and protein concentrations. In contrast, measurements in blood, sputum, exhaled breath, broncho-alveolar lavage, and lung biopsies may vary substantially over time. The best known inherited risk factor for early-onset COPD is genetically deficient plasma levels of $\alpha_{1}$-antitrypsin.

In this review we have explored potential markers of early disease and prognosis in COPD using data from the prospective epidemiological study, the Copenhagen City Heart Study, ${ }^{10-12}$ and information from two Danish National Registers covering all hospital discharges and causes of death in the country. The investigations are focused 
on genetic markers in the $\alpha_{1}$-antitrypsin and cystic fibrosis transmembrane conductance regulator (CFTR) genes, the two most important known genes for obstructive lung disease, and the MBL-2 gene in which functional polymorphisms have been associated with features of COPD in previous reports. ${ }^{13,14}$ Since COPD is defined by an abnormal inflammatory response to noxious particles or gases, elevated lung inflammation could also represent an early pathological event in COPD. Fibrinogen and C-reactive protein (CRP) correlate with degree of pulmonary inflammation during stable conditions of COPD,${ }^{15,6}$ and could potentially be useful as markers of early disease and prognosis in COPD.

\section{$\alpha_{1}$-antitrypsin deficiency and COPD}

The $\mathrm{Z}$ allele substitutes lysine for glutamic acid at position 342 in the $\alpha_{1}$-antitrypsin gene, while the $S$ allele substitutes valine for glutamic acid at position 264. The $\mathrm{Z}$ allele and to a lesser degree the $S$ allele can cause $\alpha_{1}$-antitrypsin to polymerise in hepatocytes leading to reduced plasma levels of $\alpha_{1}$-antitrypsin and higher risk for COPD. ${ }^{17}$ Severe $\alpha_{1}$-antitrypsin ZZ deficiency is the most important known genetic risk factor for COPD. Individuals with less severe $\alpha_{1}$-antitrypsin deficiency (MS, MZ, SZ genotypes) could also have an increased susceptibility for COPD. We compared plasma $\alpha_{1}$-antitrypsin level, decline in lung function, and risk of hospitalization for COPD in $\alpha_{1}$-antitrypsin MS, MZ, SZ genotypes versus. controls. ${ }^{18,19}$ We found a stepwise reduction in plasma $\alpha_{1}$-antitrypsin with increasing severity of the $\alpha_{1}$-antitrypsin genotype (Figure 1). The MZ, SZ and ZZ genotypes were associated with reduced plasma $\alpha_{1}$-antitrypsin, greater annual $\mathrm{FEV}_{1}$ decline ( $\mathrm{ZZ}$ only borderline), and with greater risks of spirometry-defined airway obstruction and COPD (MZ and SZ only borderline for airway obstruction) (Figure 1). Although MS was associated with lower plasma $\alpha_{1}$-antitrypsin level, this genotype did not confer greater $\mathrm{FEV}_{1}$ decline or increased risk of airway obstruction and COPD.

To put these results into an international context, we identified previous studies on COPD risk in intermediate $\alpha_{1}$-antitrypsin deficiency, aggregated the results using metaanalyses, and calculated summary risk estimates for COPD in MS, MZ, and SZ individuals ${ }^{20,21}$ (Figure 2). Seventeen studies were included in meta-analyses on MS, 16 in meta-analyses on MZ, and 6 in meta-analyses on SZ. The summary odds ratio for MS was increased at $1.2(1.0-1.4)$, the summary odds ratio for $\mathrm{MZ}$ was increased at 2.3 (1.6-3.4), and the summary odds ratio for SZ was increased at 3.3 (1.2-8.6). Previous publications indicate that the magnitude of the COPD risk in MZ differs by study design. Thus, we

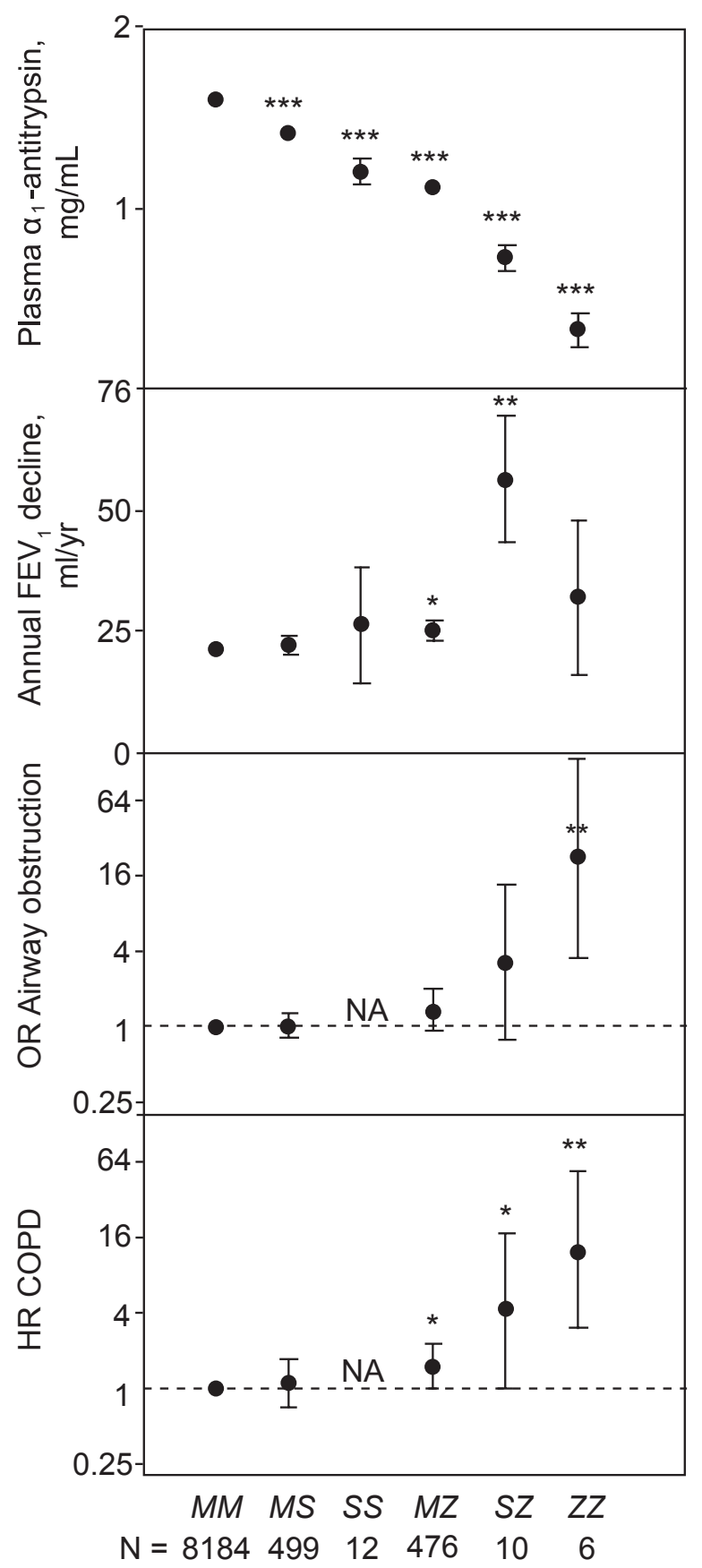

Figure I Plasma $\alpha_{1}$-antitrypsin, FEV , decline, and risk of airway obstruction or COPD by $\alpha_{1}$-antitrypsin genotype. Values are mean \pm SEM, odds ratio [OR] $(95 \% \mathrm{Cl})$, or hazard ratio [HR] $(95 \% \mathrm{Cl})$. ${ }^{* * *} \mathrm{p}<0.00 \mathrm{I}$, **p $<0.0 \mathrm{I}$, ${ }^{*} \mathrm{p}<0.05$. Data derived from Dahl M,Tybjaerg-Hansen A, Lange P, Vestbo J, Nordestgaard BG. Ann Intern Med. 2002; 136:270-279.18

performed a meta-analysis for MZ stratified by study design. After stratification, the summary odds ratio for MZ was 1.5 (0.97-2.3) in cross-sectional studies and 3.0 (2.1-4.3) in case-control studies. The summary odds ratios for MS and $\mathrm{SZ}$, and the summary odds ratio for $\mathrm{MZ}$ in cross-sectional studies, did not differ considerably from the results provided by the Copenhagen City Heart Study. ${ }^{18-21}$ 

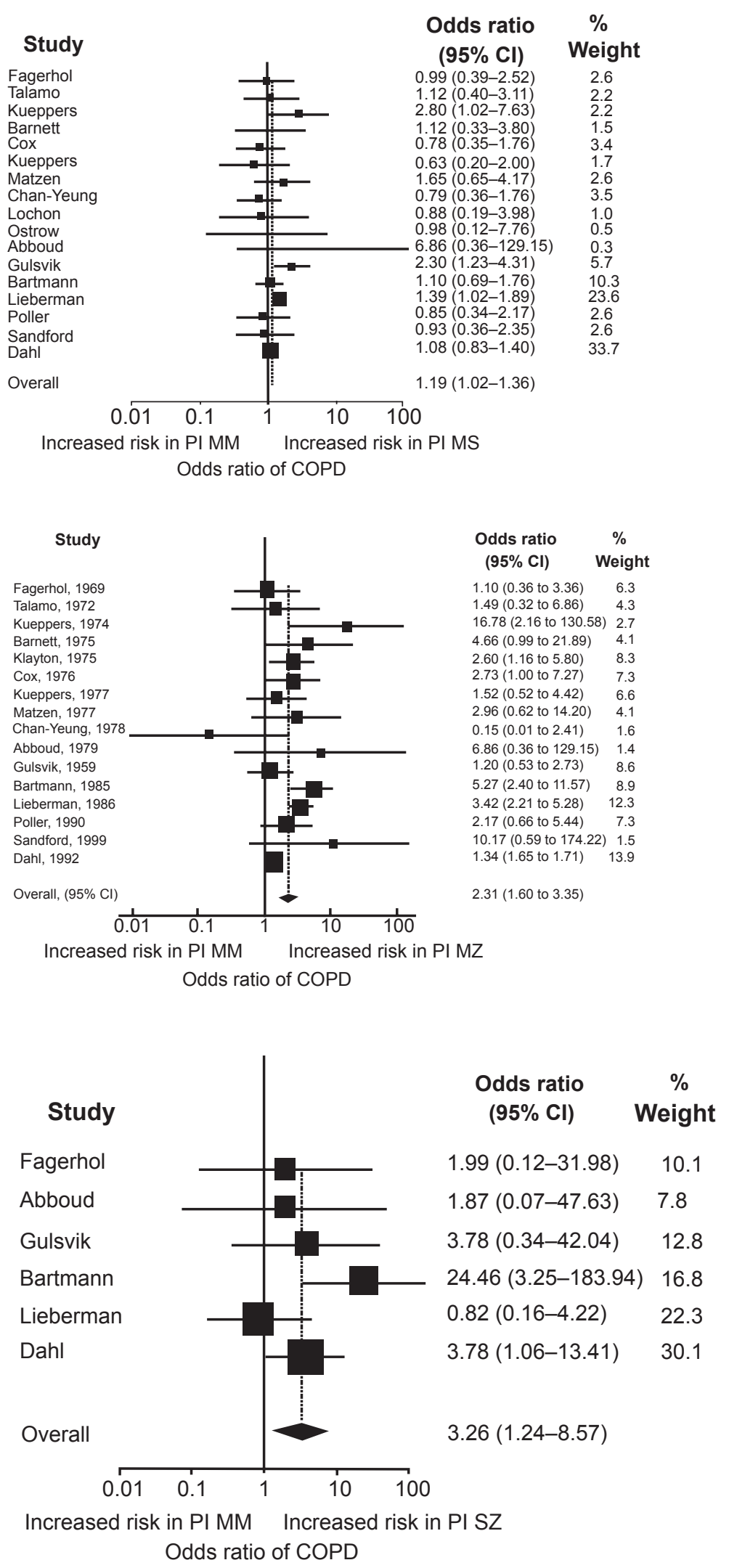

Figure 2 Cross-sectional and case-control studies of COPD risk in protease inhibitor MS, MZ, and SZ heterozygotes versus MM individuals. Box sizes are proportional to inverse-variance weights (random effects model). Lines represent 95\% confidence intervals. Adapted with permission from Dahl M, Hersh CP, Ly NP, Berkey CS, Silverman EK, Nordestgaard BG. Eur Respir J. 2005;26:67-76. ${ }^{20}$ Copyright @ 2005 European Respiratory Society Inc, and from Hersh CP, Dahl M, Ly NP, Berkey CS, Nordestgaard BG, Silverman EK. Thorax. 2004;59:843-849. ${ }^{21}$ Copyright (C BMJ Publishing Group. Abbreviation: $\mathrm{Pl}$, protease inhibitor. 
The meta-analyses suggest that risk of COPD is marginally elevated in MS and MZ individuals (in cross-sectional studies), whereas the more severe SZ genotype is an important risk factor for COPD. It is possible that MS, MZ, and SZ have greater risk estimates in subgroups of patients or in individuals with other additional risk factors for COPD, but further studies of very large populations are needed to determine if this is the case. We now offer an analysis in COPD patients that detects the $\mathrm{S}$ and $\mathrm{Z}$ alleles of the $\alpha_{1}$-antitrypsin gene with a simultaneous measurement of plasma $\alpha_{1}$-antitrypsin. ${ }^{22}$ This will help clinicians to detect $\alpha_{1}$-antitrypsin-deficient individuals with high risk of COPD, and opens up for early smoking prevention counselling and potential therapy to individuals identified with $\alpha_{1}$-antitrypsin deficiency through this new analysis.

\section{Cystic fibrosis F508del and COPD}

Cystic fibrosis is characterized by progressive obstructive lung disease in homozygous individuals, and it is possible that heterozygotes for cystic fibrosis are at increased risk of less severe forms of obstructive lung disease. To examine this, we screened 9141 individuals for the common F508del allele, and we compared lung function and prevalences of COPD and asthma in F508del heterozygous individuals versus noncarriers. ${ }^{23,24}$

Two hundred and fifty individuals were heterozygous and none homozygous for the cystic fibrosis F508del allele..$^{23,25}$ Among heterozygotes, none had previously been admitted to a hospital due to cystic fibrosis or carried an additional 394delTT or N1303K allele in the CFTR gene. ${ }^{24}$ Second to the F508del allele, the 394delTT and N1303K alleles are the two most common cystic fibrosis alleles in Denmark with allele frequencies of about $1 \%$ or more in the Danish population. ${ }^{26}$

Based on triplicate measurements of pulmonary function, we found that heterozygous individuals had lower FEV and FVC than noncarriers (Figure 3 ) ${ }^{24}$ Consistent with this, heterozygous individuals also reported that they had asthma more often than noncarriers, whereas the prevalence of COPD did not differ between the two groups (Figure 4). ${ }^{23,24}$ These findings were independent of influence from the common but less severe polythymidine tract variants in intron- 8 of the CFTR gene..$^{27}$ The shorter this polythymidine tract is, the more often exon-9 is skipped from CFTR mRNAs leading to a CFTR protein without chloride activity. ${ }^{28}$ Studies of asthma risk in cystic fibrosis heterozygotes, however, have not convincingly shown increased asthma among heterozygotes. $^{23,24,27,29-39}$ Combining all the available data from the literature in a meta-analysis, ${ }^{23,29,31,34-37,39}$ the summary odds ratio for asthma in cystic fibrosis/F508del heterozygotes is $1.3(1.1-1.6 ; \mathrm{p}=0.01)$ (Figure 5).

In conclusion, cystic fibrosis F508del heterozygotes are not at greater risk of COPD, but may be overrepresented among people with asthma and have poorer lung function than non-carriers. Combining recent reports from the literature, the risk for asthma in cystic fibrosis heterozygotes is roughly $30 \%$ elevated. Thus, F508del cannot be used as a biomarker for COPD or asthma in clinical settings. It is possible that F508del can be used as a clinical marker for asthma in certain subgroups of patients in the future, when other susceptibility markers for asthma are available.

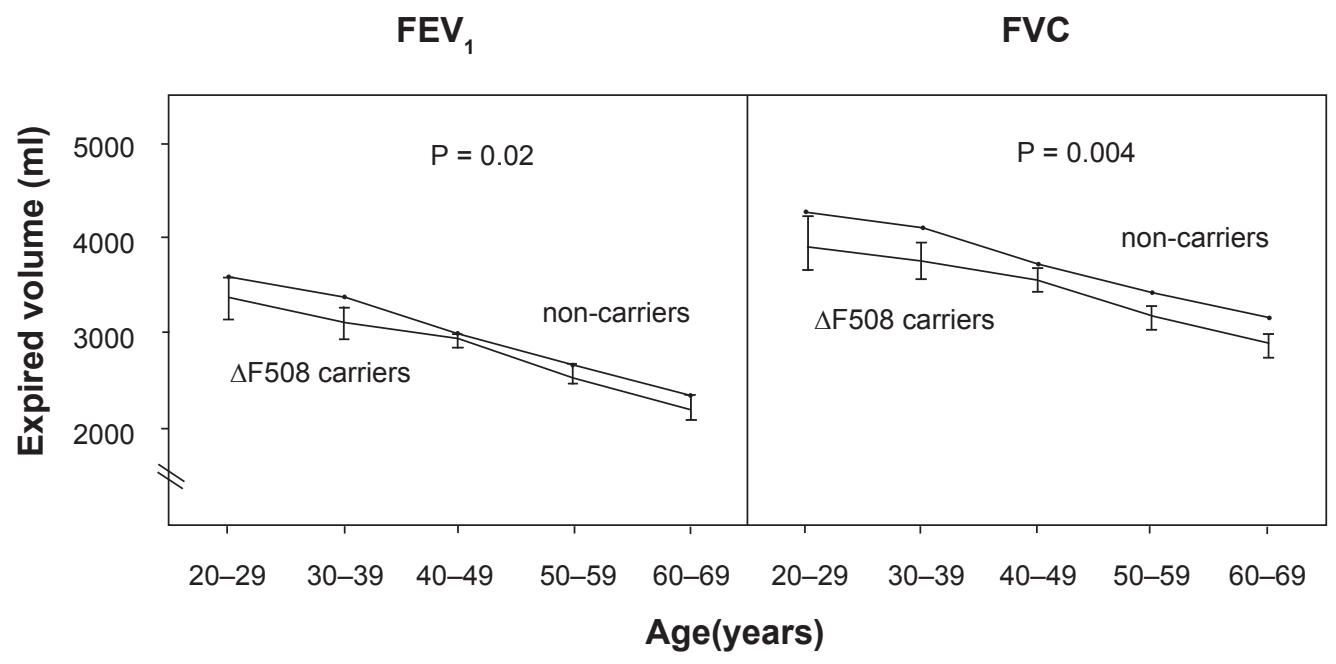

Figure 3 Levels of FEV, and FVC by cystic fibrosis F508del carrier status. Values are means \pm SEM, based on I0-year age groups. Number of measurements: F508del, $n=270$; and noncarriers, $n=10,002$. P-values are by general linear repeated-measures analysis comparing F508del heterozygotes versus noncarriers. Adapted with permission from Dahl M, Nordestgaard BG, Lange P,Tybjaerg-Hansen A.J Allergy Clin Immunol. 200 I; 107:8I8-823.24 Copyright (C) Elsevier. 


\section{Cystic fibrosis F508del heterozygotes}

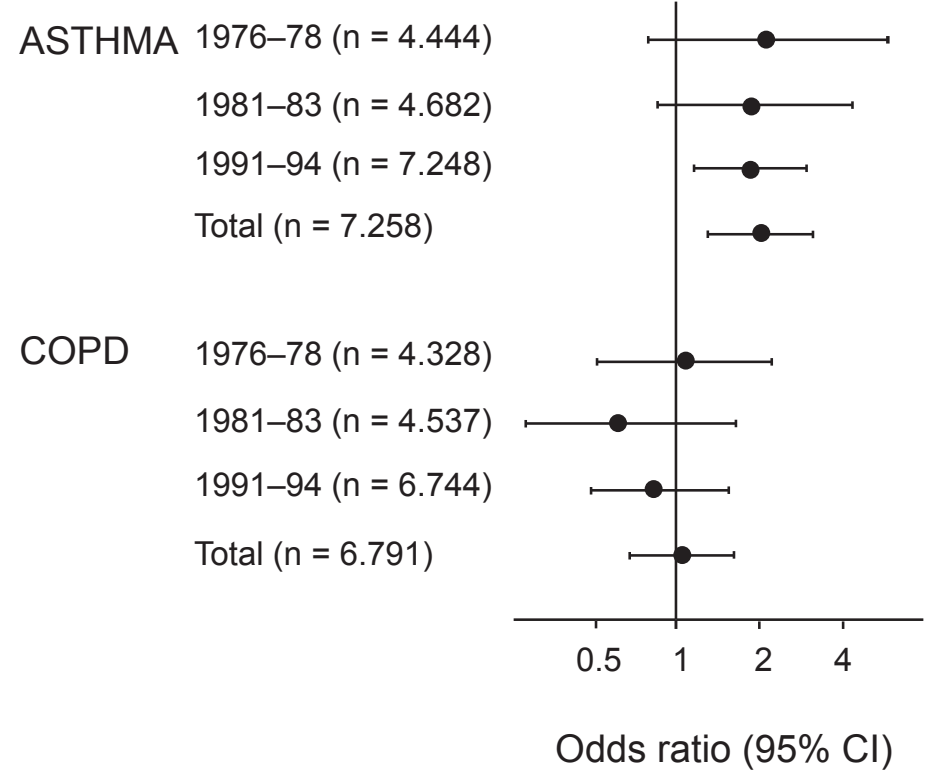

Figure 4 Odds ratios for asthma and COPD in cystic fibrosis F508del heterozygotes versus noncarriers in the 1976 to I978, I98I to I983, and I99 I to I994 examinations of the Copenhagen City Heart Study. Multiple logistic regression analyses allowed for age, sex, tobacco consumption, passive smoking history, and familial asthma."Total" refers to disease diagnosed at at least one examination. Adapted with permission from DahI M, Nordestgaard BG, Lange P,Tybjaerg-Hansen A.JAllergy Clin Immunol. 200 ;; 107:8I8-823. ${ }^{24}$ Copyright (C) Elsevier.

\section{Mannose-binding lectin and COPD} Mannose-binding lectin (MBL) is an acute phase protein secreted from the liver. ${ }^{40,41}$ It has antibody-like function in the innate immune system, where it binds sugarmoieties on microorganisms and on apoptotic cells. Bound MBL can clear its targets through promoting opsonophagocytosis or by activating the complement system through MBL-associated protease 1 and 2. Deficiency of MBL levels/activity in plasma due to polymorphisms in the MBL-2 gene is thought to weaken normal innate immune functions against microorganisms and apoptotic cells in the body. ${ }^{42}$ Genetically reduced
MBL in plasma raises the susceptibility for disease in COPD and asthma. ${ }^{13,14,43}$ Thus, we determined the risk of COPD and asthma in MBL deficient individuals versus controls in our study of the population at large. ${ }^{44} \mathrm{We}$ did not find an increased risk of COPD or asthma with MBL deficiency (Figure 6). The risk of death due to respiratory disease was unaffected by MBL deficiency status.

Only few other studies have examined the potential relation between MBL deficiency and obstructive lung disease. . $^{13,14,43}$ Our study had ample statistical power to test the hypothesis that MBL deficiency is associated with risk of obstructive

\begin{tabular}{|c|c|c|c|c|c|c|}
\hline \multirow[t]{2}{*}{ Study name } & \multicolumn{4}{|c|}{ Statistics for each study } & \multicolumn{2}{|c|}{ Asthma/Total } \\
\hline & $\begin{array}{c}\text { Odds } \\
\text { ratio }\end{array}$ & $\begin{array}{l}\text { Lower } \\
\text { limit }\end{array}$ & $\begin{array}{l}\text { Upper } \\
\text { limit }\end{array}$ & $p$-value & $\begin{array}{c}\mathrm{CF} \\
\text { hetero }\end{array}$ & noncarriers \\
\hline Dahl & 1.60 & 1.03 & 2.48 & 0.03 & $23 / 250$ & $529 / 8891$ \\
\hline Lowenfels & 1.30 & 0.92 & 1.83 & 0.13 & $107 / 1113$ & $52 / 688$ \\
\hline Munth e-kaas & 1.22 & 0.60 & 2.48 & 0.58 & $13 / 34$ & $223 / 663$ \\
\hline Castellani & 1.16 & 0.46 & 2.90 & 0.74 & $12 / 261$ & 8/201 \\
\hline de cid & 0.77 & 0.42 & 1.43 & 0.41 & $25 / 47$ & $222 / 374$ \\
\hline Lazaro & 14.44 & 0.85 & 243.83 & 0.06 & $21 / 21$ & $123 / 164$ \\
\hline Mennie & 0.99 & 0.46 & 2.12 & 0.99 & $11 / 186$ & $20 / 337$ \\
\hline Tzetis & 4.50 & 1.41 & 14.34 & 0.01 & $9 / 17$ & $11 / 55$ \\
\hline Overall & 1.31 & 1.06 & 1.62 & 0.01 & & \\
\hline
\end{tabular}

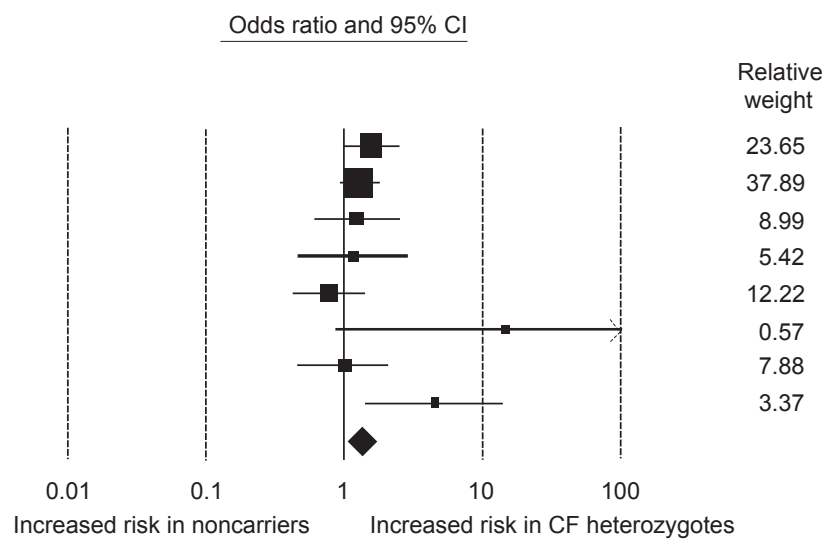

Figure 5 Cross-sectional and case-control studies of asthma risk in cystic fibrosis/F508del heterozygotes. Box sizes are proportional to inverse-variance weights (random effects model). Lines represent $95 \%$ confidence intervals. 


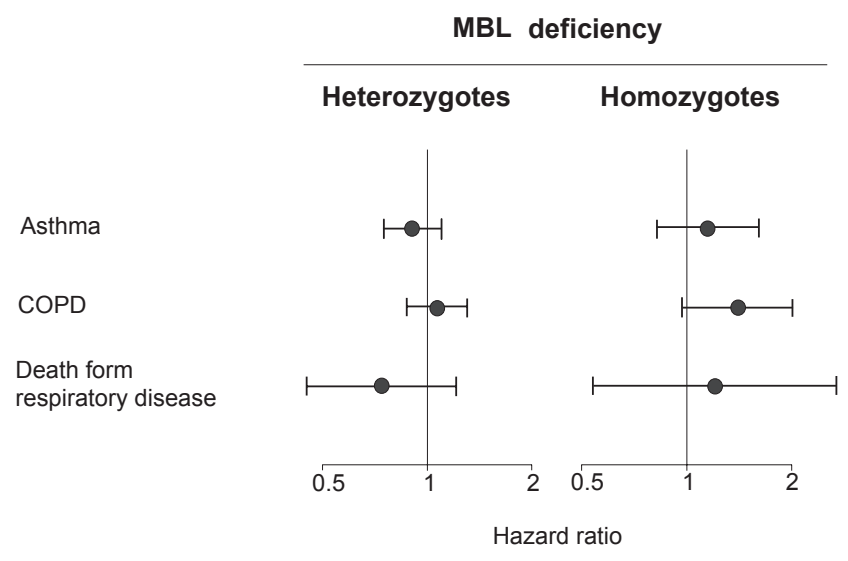

Figure 6 Hazard ratios for asthma and COPD by mannose-binding lectin deficiency. Adapted with permission from Dahl M, Tybjaerg-Hansen A, Schnohr P, Nordestgaard BG.J Exp Med. 2004;199:139|-1399.44 Copyright (C 2004 Rockefeller University Press.

lung disease. In conclusion, genetic MBL deficiency is not a major risk factor for COPD in the Danish general population. At present, genetic variants in the MBL-2 gene cannot be used as biomarkers of obstructive lung disease.

In children, MBL could have an important function in pulmonary host defence during the vulnerable period when the adaptive immune system is immature. ${ }^{45}$ We tested whether adult MBL deficient individuals more often than controls were hospitalized or died due to pulmonary infection, but found no increased frequency of pulmonary infection with MBL deficiency. ${ }^{44}$ These results suggest that MBL does not have a major role in pulmonary defence against microorganisms in adult Danish individuals.

\section{Other genetic markers of COPD}

We have used a candidate gene approach to evaluate genetic markers in the $\alpha_{1}$-antitrypsin, CFTR, and MBL genes, and their relation to COPD. Other approaches include linkage studies, transcript-expression analyses, and animal model genetics, all of which can be used to identify certain genetic candidates for COPD. To translate results from such studies into clinical medicine, an estimation of risk of disease is needed. This can be achieved through association studies of the population at large such as ours.

In COPD recent focus has been on the enzyme serine proteinase inhibitor E2 (SERPINE2), as this enzyme is a family relative of $\alpha_{1}$-antitrypsin (SERPINA1), the most important risk factor of inherited COPD. Supporting that SERPINE2 is of importance to COPD susceptibility, polymorphisms in the SERPINE2 gene have been shown to associate with features of COPD. ${ }^{46,47}$ The enzymes epoxide hydrolase 1
(EPHX1) and superoxide dismutase 3 (SOD3) are also of potential interest as markers in COPD,${ }^{48-51}$ as these enzymes may inhibit increased oxidative stress in the lungs due to cigarette smoke inhalations. Comprehensive reviews on other candidate genes in COPD are readily available..$^{52,53}$

\section{Plasma fibrinogen and COPD}

Pulmonary inflammation in COPD is associated with increased levels of acute phase reactants in plasma, and these reactants could potentially be used to predict risk of future COPD events. To test whether the acute phase reactant fibrinogen predicts future COPD, we determined lung function and relative risk of COPD hospitalization in individuals with increased levels of plasma fibrinogen. We found that individuals with baseline plasma fibrinogen of more than $3.3 \mathrm{~g} / \mathrm{L}$ versus less than $2.7 \mathrm{~g} / \mathrm{L}$ had reduced lung function, increased cumulative incidence of COPD hospitalization (Figure 7), and an increased relative risk of 1.7 (1.1-2.6) for COPD hospitalization during 6 years of follow-up. ${ }^{54}$ These findings suggest that plasma fibrinogen is a significant predictor of future COPD in the population at large.

A later study confirms plasma fibrinogen as a marker of COPD prognosis: Gan et al estimated a $0.37 \mathrm{~g} / \mathrm{L}$ difference in plasma fibrinogen between COPD patients and controls. ${ }^{15}$ The clinical utility of plasma fibrinogen as a biomarker of COPD seems limited based on its low predictive value for COPD $.{ }^{54} \mathrm{IL}-6$ regulates fibrinogen production from the liver. Thus, the results point to an important function for fibrinogen, IL-6, or factors upstream of IL-6 in the pathogenesis of COPD. Further studies are required to elucidate which part, if any, fibrinogen or IL-6 has in the progression of COPD.

\section{Plasma C-reactive protein and COPD}

COPD is associated with elevated C-reactive protein (CRP) concentration in serum which equals concentrations in plasma, ${ }^{15}$ and it is possible that CRP as a marker of pulmonary inflammation could be used to predict risk of future COPD events. To test whether plasma CRP predicts future COPD events, we measured CRP in a subgroup of individuals with high risk of clinical COPD, that is, individuals with spirometry-defined airway obstruction. ${ }^{55}$ During 8 years of follow-up, we recorded admissions and deaths due to COPD, and relative risks for COPD hospitalization or deaths were determined. We found that individuals with serum CRP of more than $3 \mathrm{mg} / \mathrm{L}$ versus $\leq 3 \mathrm{mg} / \mathrm{L}$ at baseline had increased cumulative incidence of COPD hospitalization and death (Figure 8), an increased hazard ratio of $1.4(1.0-2.0)$ for 
COPD hospitalization, and an increased hazard ratio of 2.2 (1.2-3.9) for COPD death. ${ }^{55}$ Absolute risks for COPD hospitalization and death increased with baseline serum CRP levels (Figure 9). The highest absolute 10-year risks for COPD hospitalization and death were 54\% and 57\% among individuals with baseline CRP above $3 \mathrm{mg} / \mathrm{L}$, above 70 years of age, with a tobacco consumption of more than $15 \mathrm{~g} /$ day, and an $\mathrm{FEV}_{1} \%$ predicted less than $50 \%$.

The data suggests an important role for CRP, or its main regulatory cytokine IL-6, in COPD progression and development. Supporting a role for IL-6 in COPD pathogenesis, IL-6 may stimulate inflammatory cell recruitment to the lung, and lead to emphysema-like airspace enlargement and respiratory muscle wasting in animal models of lung disease. ${ }^{56-65}$ Thus, our own and previous data seem to suggest that IL-6 or factors upstream of IL- 6 are involved in the pathogenesis of COPD. In the future, CRP levels could be used clinically to assess prognosis in patients with airway obstruction. High absolute risk as depicted in Figure 9 may motivate patients at the highest risk to quit smoking or to receive medication.

\section{Other biochemical markers of COPD}

In COPD, biochemical biomarkers represent a new field that we have just begun to explore. The potential is great. COPD is a multicomponent disease for which airway inflammation plays an imperative role. This component, among several others, needs descriptive measures to provide a more comprehensive and clinically accurate assessment of COPD.

Biochemical COPD markers can be measured in exhaled breath, induced sputum, bronchoalveolar lavage fluid, lung biopsies, and plasma. Compared to biomarkers measured in other sample material, biochemical markers determined in plasma are reliably measured using equipment that is costeffective and readily available in clinical settings. However, biochemical markers, and in particular those measured in plasma, may be modulated by morbidities other than COPD, and thus may in some circumstances represent epiphenomena unrelated to the COPD phenotype.

The validation of a biomarker has been proposed to involve the following three phases: ${ }^{8} 1$ ) demonstration that the marker frequency/magnitude is associated with a clinical outcome. 2) Phase I/II trials demonstrating effects on the marker with therapeutic intervention. Are there dose-dependent effects of treatment on the marker? 3) Demonstration that treatmentrelated changes in the marker are associated with positive changes in clinical outcomes. Is the marker applicable to all disease stages and all interventions?

In COPD the biochemical markers are many, but these have been less well investigated than biochemical markers

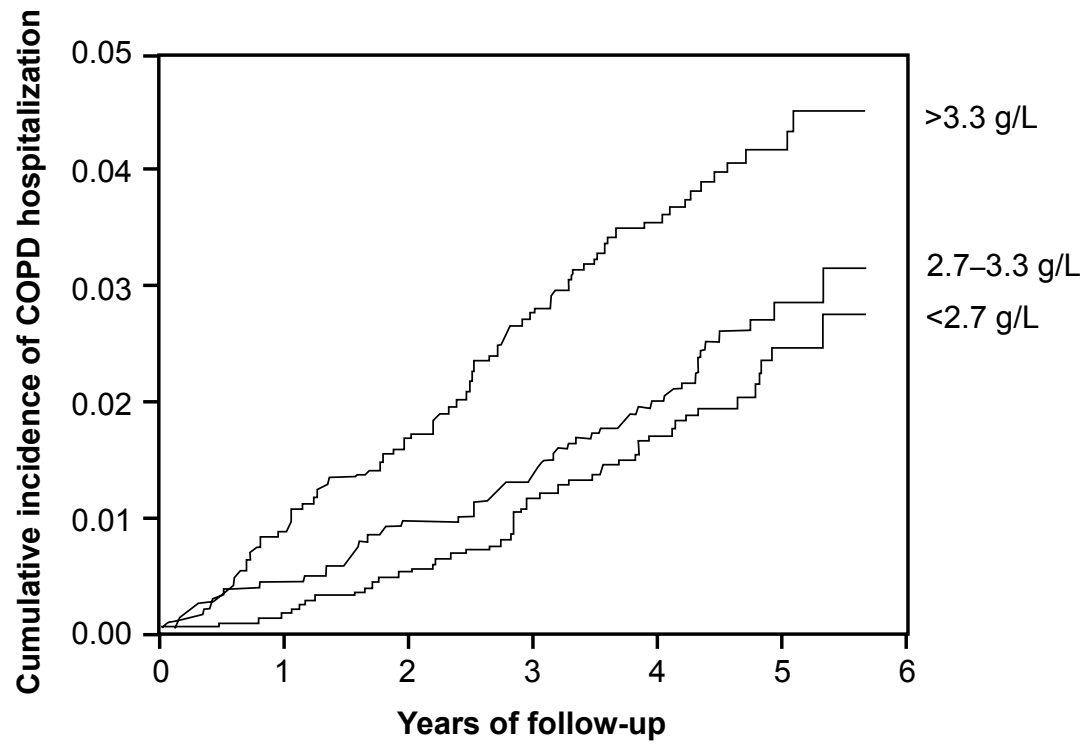

No. at risk

$\begin{array}{lllllll}<2.7 \mathrm{~g} / \mathrm{L} & 2985 & 2916 & 2884 & 2825 & 2298 & 1051 \\ 2.7-3.3 \mathrm{~g} / \mathrm{L} & 2984 & 2907 & 2856 & 2801 & 2230 & 1004 \\ >3.3 \mathrm{~g} / \mathrm{L} & 2986 & 2811 & 2734 & 2646 & 2107 & 1019\end{array}$

Figure 7 Kaplan-Meier curves showing rate of COPD hospitalizations during follow-up. Number at risk at the beginning of each year is shown below the horizontal axis. $P<0.00 \mathrm{I}$ for plasma fibrinogen $>3.3 \mathrm{~g} / \mathrm{L}$ versus $<2.7 \mathrm{~g} / \mathrm{L}, \mathrm{P}=0.003 \mathrm{for}>3.3 \mathrm{~g} / \mathrm{L}$ versus $2.7-3.3 \mathrm{~g} / \mathrm{L}$, and $\mathrm{p}=0.3 \mathrm{I}$ for $2.7-3.3 \mathrm{~g} / \mathrm{L}$ versus $<2.7 \mathrm{~g} / \mathrm{L}$ on log-rank test.Adapted with permission from Dahl M, Tybjaerg-Hansen A,Vestbo J, Lange P, Nordestgaard BG. Am J Respir Crit Care Med. 200 I; 164: 1008-101 I. ${ }^{54}$ Copyright @ 2001 American Thoracic Society. 


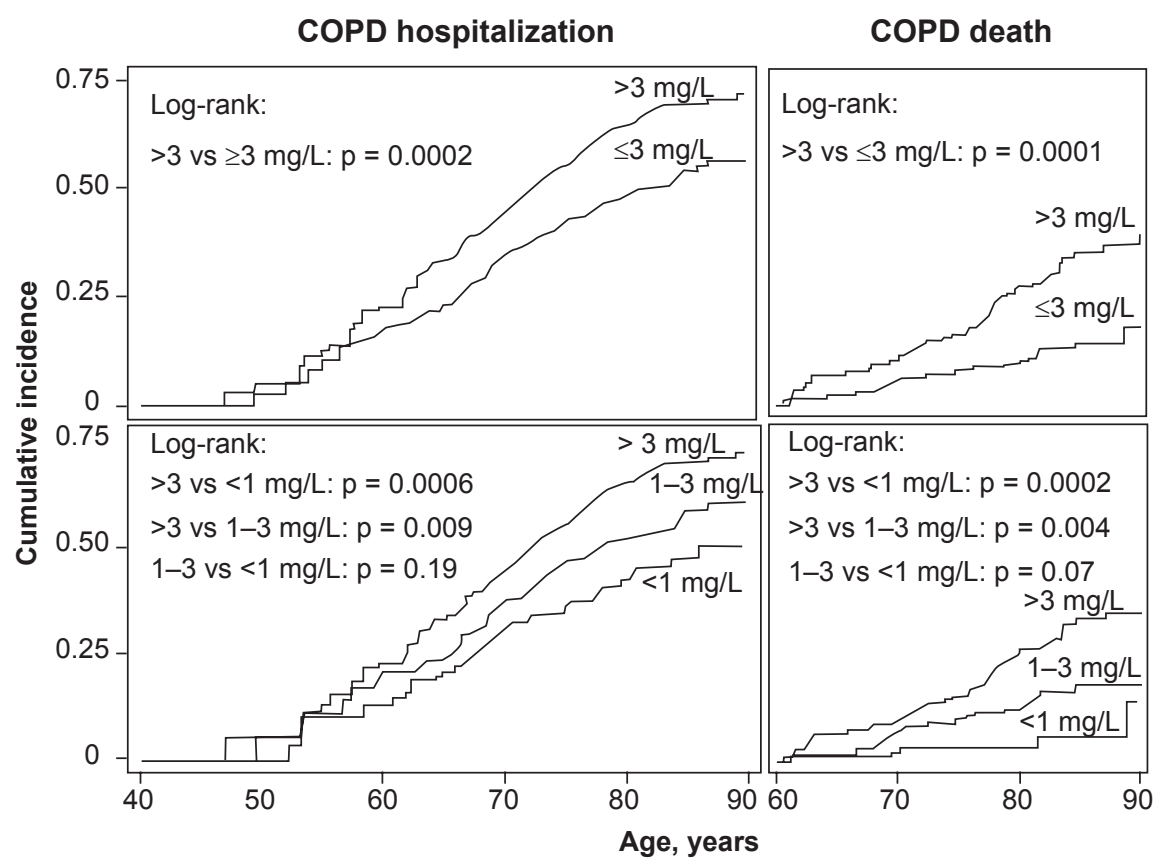

Figure 8 Cumulative incidence of COPD events according to baseline serum CRP levels. Cumulative incidences of COPD hospitalization and death were increased in individuals with baseline CRP $>3 \mathrm{mg} / \mathrm{L}$ versus $\leq 3 \mathrm{mg} / \mathrm{L}$.Adapted with permission from Dahl M,Vestbo J, Lange P, Bojesen SE,Tybjaerg-Hansen A, Nordestgaard BG. Am J Respir Crit Care Med. 2007; 175:250-255.55 Copyright @ 2007 American Thoracic Society.

in asthma. When evaluating therapies for COPD, markers that could surrogate for critical pathological processes in COPD would be highly warranted. For example desmosine as part of mature elastin indicates elevated turnover of elastic fibres in COPD. ${ }^{66}$ Novel lung-specific markers also appear promising, ${ }^{67,68}$ in particular surfactant protein-A, which is elevated in lung tissue and sputum in COPD patients when compared with controls in a proteomics study. ${ }^{69}$ The exploration and validation of potential markers for COPD is currently ongoing and no specific marker has so far been implemented for clinical use. ${ }^{7-9,70-72}$

\section{Conclusions}

Using data from up to 9245 adult participants from the Copenhagen City Heart Study and information from the national Danish Hospital Discharge Registry and the national Danish Causes of Death Registry, we explored new potential markers of COPD.

The risk of COPD is marginally elevated for the genetic biomarkers, MS and MZ, in the $\alpha_{1}$-antitrypsin gene, whereas the SZ biomarker is an important risk factor of COPD. The ZZ genotype is already in clinical use as a genetic marker for early-onset COPD. We have set-up an analysis for diagnosing the $\mathrm{SZ}$ and $\mathrm{ZZ}$ genotypes together with measurement of plasma $\alpha_{1}$-antitrypsin levels to be used broadly, including in COPD patients. This will help clinicians to detect $\alpha_{1}$-antitrypsin-deficient individuals with a high risk for COPD, and opens up for early smoking prevention counseling and potential therapy for individuals identified with $\alpha_{1}$-antitrypsin deficiency through this new analysis.

The genetic biomarker, F508del, in the cystic fibrosis gene was not associated with COPD, but with increased asthma risk. Aggregating results from previous reports, the risk of asthma is only marginally elevated. Thus, F508del cannot at present be used as a marker of COPD or asthma in clinical settings.

Genetic deficiency of MBL is not a major risk factor for COPD or asthma, and it appears that genetic variants in the MBL-2 gene cannot at present be used as biomarkers for obstructive lung disease in the Danish population.

Elevated plasma fibrinogen and CRP levels were associated with increased COPD risk and may be good for prognostication once a diagnosis of COPD has been established. In the future after further validation, it is possible that these markers, particularly CRP, can be used to categorise individuals with low, medium, or high risk of COPD, and thus point out patients in need of intensified prevention and treatment for COPD. Furthermore, the observed association between COPD and elevated fibrinogen and CRP levels suggests that either factor or upstream factors regulating fibrinogen and CRP expression are important players in the pathogenesis 

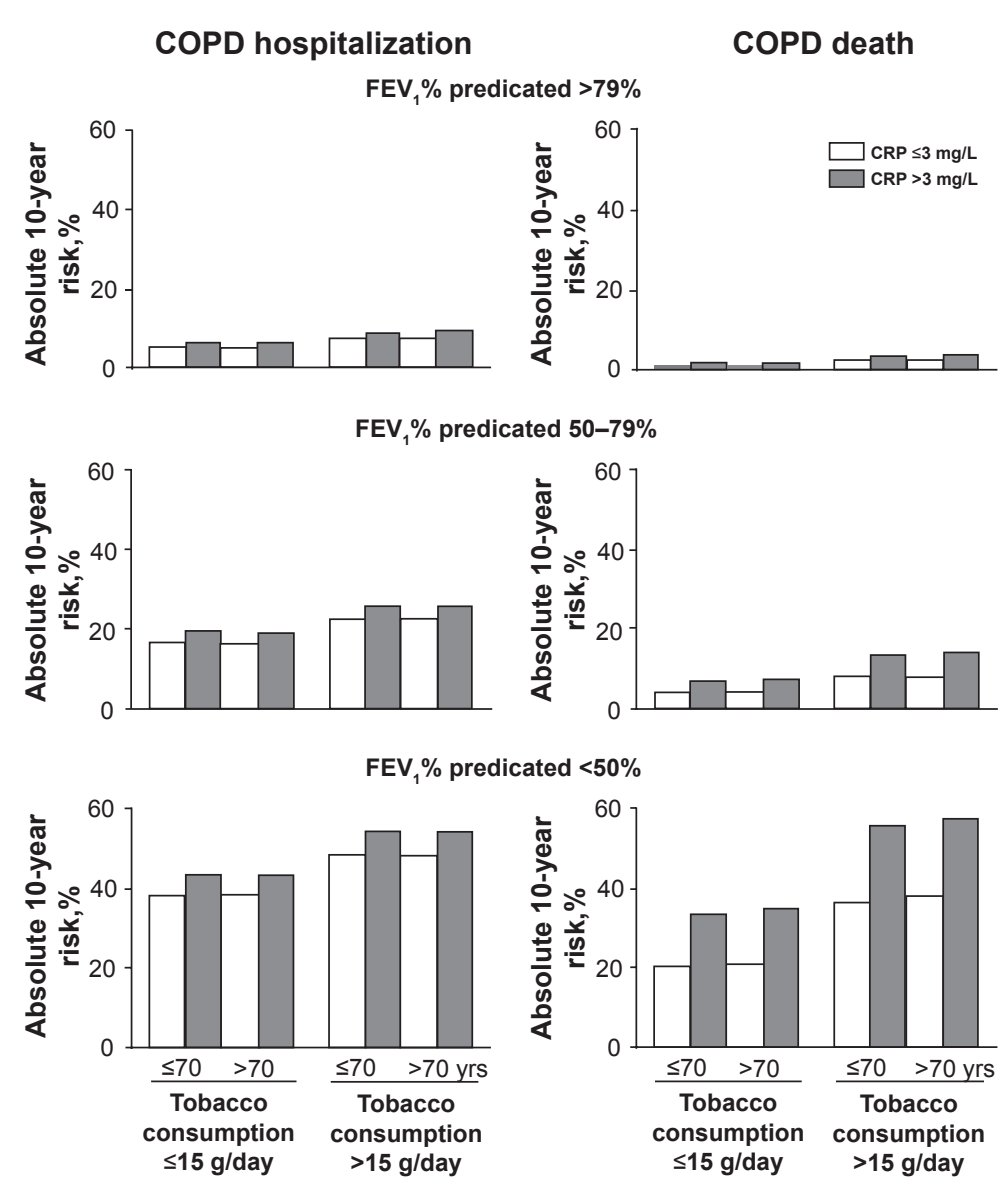

Figure 9 Absolute 10-year risks of COPD hospitalization and COPD death according to FEV \% predicted, tobacco consumption, age, and serum CRP. The dependent variables for the Poisson regressions are number of COPD hospitalizations or COPD deaths during the subsequent 10 years. The highest absolute 10 -year risks for COPD hospitalization and death $-54 \%$ and $57 \%$ - were found among individuals with CRP $>3 \mathrm{mg} / \mathrm{L}$, above 70 years of age, with tobacco consumption $>15 \mathrm{~g} / \mathrm{day}$, and $\mathrm{FEV} \%$ predicted $<50 \%$. Adapted with permission from Dahl M,Vestbo J, Lange P, Bojesen SE, Tybjaerg-Hansen A, Nordestgaard BG. Am J Respir Crit Care Med. 2007; I75:250-255..$^{55}$ Copyright @ 2007 American Thoracic Society.

of COPD. To determine whether fibrinogen or CRP are causally related to COPD, we are currently investigating if genetically increased levels of fibrinogen and CRP are associated with increased risk of future COPD. We anticipate that fibrinogen and CRP-regulating factors (IL-6, TNF- $\alpha$, IL-1) rather than fibrinogen and CRP themselves are involved in COPD pathogenesis, as IL-6, TNF- $\alpha$, and IL-1 are already factors with established functions in COPD. IL- 6 is involved in inflammation, vascular permeability, and cell proliferation, while TNF- $\alpha$, and IL-1 initiates and maintains inflammation, and activates endothelial and epithelial cells. ${ }^{6}$

The best known early disease markers for COPD remain genetic variations in alpha-1-antitrypsin. They cause lifelong reduced levels of alpha-1-antitrypsin in plasma and increase the risk for COPD. As such, future studies on markers in COPD should ideally demonstrate association between a marker and COPD, as well as change in the COPD risk with changes in the marker concentration or function (genetically or medically induced). Randomized pharmacological trials or mendelian randomization designs are useful in this regard and will enable us to assess the importance of early markers for COPD much better. The study of disease markers in COPD can improve the phenotyping of different types of COPD. Linking the markers to critical pathologic events in COPD can provide novel insights into the pathogenesis of COPD. With the recent focus on heterogeneity in COPD and the mounting efforts in identifying novel markers for COPD this research field seems in progress.

\section{Acknowledgments}

Supported by the Danish Lung Association, Danish Heart Foundation, and Copenhagen County Foundation.

\section{Disclosures}

Neither author has conflicts of interest to disclose. 


\section{References}

1. Pauwels RA, Buist AS, Calverley PM, Jenkins CR, Hurd SS. Global strategy for the diagnosis, management, and prevention of chronic obstructive pulmonary disease. NHLBI/WHO Global Initiative for Chronic Obstructive Lung Disease (GOLD) Workshop summary. Am J Respir Crit Care Med. 2001;163:1256-1276.

2. Mathers CD, Loncar D. Projections of global mortality and burden of disease from 2002 to 2030. PLoS Med. 2006;3:e442.

3. Dahl M, Bauer AK, Arredouani M, et al. Protection against inhaled oxidants through scavenging of oxidized lipids by macrophage receptors MARCO and SR-AI/II. J Clin Invest. 2007;117:757-764.

4. Owen CA. Roles for proteinases in the pathogenesis of chronic obstructive pulmonary disease. Int J Chron Obstruct Pulmon Dis. 2008;3:253-268.

5. Taraseviciene-Stewart L, Voelkel NF. Molecular pathogenesis of emphysema. J Clin Invest. 2008;118:394-402.

6. Yoshida T, Tuder RM. Pathobiology of cigarette smoke-induced chronic obstructive pulmonary disease. Physiol Rev. 2007;87:1047-1082.

7. Cazzola M, MacNee W, Martinez FJ, et al. Outcomes for COPD pharmacological trials: from lung function to biomarkers. Eur Respir J. 2008;31:416-469.

8. Jones PW, Agusti AG. Outcomes and markers in the assessment of chronic obstructive pulmonary disease. Eur Respir J. 2006;27:822-832.

9. Vestbo J, Anderson W, Coxson HO, et al. Evaluation of COPD Longitudinally to Identify Predictive Surrogate End-points (ECLIPSE). Eur Respir J. 2008;31:869-873.

10. Epidemiology of chest pain and angina pectoris, with special reference to treatment needs. Acta Med Scand Suppl. 1984;682:1-120.

11. The Copenhagen City Heart Study. Osterbroundersogelsen. A book of tables with data from the first examination (1976-78) and a five year follow-up (1981-83). The Copenhagen City Heart Study Group. Scand J Soc Med Suppl. 1989;41:1-160.

12. Schnohr P, Jensen G, Lange P, Scharling H, Appleyard M. The Copenhagen City Heart Study - Østerbroundersøgelsen. Tables with data from the third examination 1991-1994. Eur Heart J Suppl. 2001;3:H1-H83.

13. Garcia-Laorden MI, Sole-Violan J, Rodriguez DC, et al. Mannose-binding lectin and mannose-binding lectin-associated serine protease 2 in susceptibility, severity, and outcome of pneumonia in adults. J Allergy Clin Immunol. 2008;122:368-74, 374.

14. Yang IA, Seeney SL, Wolter JM, et al. Mannose-binding lectin gene polymorphism predicts hospital admissions for COPD infections. Genes Immun. 2003;4:269-274.

15. Gan WQ, Man SF, Senthilselvan A, Sin DD. Association between chronic obstructive pulmonary disease and systemic inflammation: a systematic review and a meta-analysis. Thorax. 2004;59:574-580.

16. Olafsdottir IS, Gislason T, Thjodleifsson B, et al. Gender differences in the association between C-reactive protein, lung function impairment, and COPD. Int J Chron Obstruct Pulmon Dis. 2007;2:635-642.

17. Gooptu B, Lomas DA. Polymers and inflammation: disease mechanisms of the serpinopathies. J Exp Med. 2008;205:1529-1534.

18. Dahl M, Tybjaerg-Hansen A, Lange P, Vestbo J, Nordestgaard BG. Change in lung function and morbidity from chronic obstructive pulmonary disease in alpha1-antitrypsin MZ heterozygotes: A longitudinal study of the general population. Ann Intern Med. 2002;136:270-279.

19. Dahl M, Nordestgaard BG, Lange P, Vestbo J, Tybjaerg-Hansen A. Molecular diagnosis of intermediate and severe alpha(1)-antitrypsin deficiency: MZ individuals with chronic obstructive pulmonary disease may have lower lung function than MM individuals. Clin Chem. 2001;47:56-62.

20. Dahl M, Hersh CP, Ly NP, Berkey CS, Silverman EK, Nordestgaard BG. The protease inhibitor PI*S allele and COPD: a meta-analysis. Eur Respir J. 2005;26:67-76.

21. Hersh CP, Dahl M, Ly NP, Berkey CS, Nordestgaard BG, Silverman EK. Chronic obstructive pulmonary disease in alpha1-antitrypsin PI MZ heterozygotes: a meta-analysis. Thorax. 2004;59:843-849.
22. Dahl M, Nordestgaard BG, Tybjærg-Hansen A. Molecular diagnosis of intermediate and severe alpha1-antitrypsin deficiency by use of multiplex polymerase chain reaction. In: Bruns DE, Lo YMD, Wittwer CT, eds. Molecular testing in laboratory medicine. Washington DC: AACC Press; 2002. p. 250-258.

23. Dahl M, Tybjaerg-Hansen A, Lange P, Nordestgaard BG. DeltaF508 heterozygosity in cystic fibrosis and susceptibility to asthma. Lancet. 1998;351:1911-1913.

24. Dahl M, Nordestgaard BG, Lange P, Tybjaerg-Hansen A. Fifteen-year follow-up of pulmonary function in individuals heterozygous for the cystic fibrosis phenylalanine-508 deletion. J Allergy Clin Immunol. 2001;107:818-823.

25. Dahl M, Tybjaerg-Hansen A, Wittrup HH, Lange P, Nordestgaard BG. Cystic fibrosis Delta F508 heterozygotes, smoking, and reproduction: studies of 9141 individuals from a general population sample. Genomics. 1998;50:89-96.

26. Estivill X, Bancells C, Ramos C. Geographic distribution and regional origin of 272 cystic fibrosis mutations in European populations. The Biomed CF Mutation Analysis Consortium. Hum Mutat. 1997;10:135-154.

27. Dahl M, Tybjaerg-Hansen A, Lange P, Nordestgaard BG. Asthma and COPD in cystic fibrosis intron-8 5 T carriers. A population-based study. Respir Res. 2005;6:113.

28. Delaney SJ, Rich DP, Thomson SA, et al. Cystic fibrosis transmembrane conductance regulator splice variants are not conserved and fail to produce chloride channels. Nat Genet. 1993;4:426-431.

29. Castellani C, Quinzii C, Altieri S, Mastella G, Assael BM. A pilot survey of cystic fibrosis clinical manifestations in CFTR mutation heterozygotes. Genet Test. 2001;5:249-254.

30. Conneally PM, Merritt AD, Yu PL. Cystic fibrosis: population genetics. Tex Rep Biol Med. 1973;31:639-650.

31. de Cid R, Chomel JC, Lazaro C, et al. CFTR and asthma in the French EGEA study. Eur J Hum Genet. 2001;9:67-69.

32. Griesenbach U, Geddes DM, Alton EW. The pathogenic consequences of a single mutated CFTR gene. Thorax. 1999;54 Supp1 2:S19-S23.

33. Hoffjan S, Nicolae D, Ober C. Association studies for asthma and atopic diseases: a comprehensive review of the literature. Respir Res. 2003;4:14.

34. Lazaro C, de Cid R, Sunyer J, et al. Missense mutations in the cystic fibrosis gene in adult patients with asthma. Hum Mutat. 1999; $14: 510-519$.

35. Lowenfels AB, Maisonneuve P, Palys B, Schoni MH, Redemann B. DeltaF508 heterozygosity and asthma. Lancet. 1998;352:985-987.

36. Mennie M, Gilfillan A, Brock DJ, Liston WA. Heterozygotes for the delta F508 cystic fibrosis allele are not protected against bronchial asthma. Nat Med. 1995;1:978-979.

37. Munthe-Kaas MC, Lodrup Carlsen KC, Carlsen KH, et al. CFTR gene mutations and asthma in the Norwegian Environment and Childhood Asthma study. Respir Med. 2006;100:2121-2128.

38. Schroeder SA, Gaughan DM, Swift M. Protection against bronchial asthma by CFTR delta F508 mutation: a heterozygote advantage in cystic fibrosis. Nat Med. 1995;1:703-705.

39. Tzetis M,Efthymiadou A, Strofalis S, et al.CFTR gene mutations-including three novel nucleotide substitutions - and haplotype background in patients with asthma, disseminated bronchiectasis and chronic obstructive pulmonary disease. Hum Genet. 2001;108:216-221.

40. Holmskov U, Thiel S, Jensenius JC. Collections and ficolins: humoral lectins of the innate immune defense. Annu Rev Immunol. 2003;21:547-578

41. Turner MW. The role of mannose-binding lectin in health and disease. Mol Immunol. 2003;40:423-429.

42. Eisen DP, Minchinton RM. Impact of mannose-binding lectin on susceptibility to infectious diseases. Clin Infect Dis. 2003;37:1496-1505.

43. Nagy A, Kozma GT, Keszei M, Treszl A, Falus A, Szalai C. The development of asthma in children infected with Chlamydia pneumoniae is dependent on the modifying effect of mannose-binding lectin. J Allergy Clin Immunol. 2003;112:729-734. 
44. Dahl M, Tybjaerg-Hansen A, Schnohr P, Nordestgaard BG. A population-based study of morbidity and mortality in mannose-binding lectin deficiency. J Exp Med. 2004;199:1391-1399.

45. Koch A, Melbye M, Sorensen P, et al. Acute respiratory tract infections and mannose-binding lectin insufficiency during early childhood. JAMA. 2001;285:1316-1321.

46. Demeo DL, Mariani TJ, Lange C, et al. The SERPINE2 Gene Is Associated with Chronic Obstructive Pulmonary Disease. Am J Hum Genet. 2006;78:253-264.

47. Zhu G, Warren L, Aponte J, et al. The SERPINE2 gene is associated with chronic obstructive pulmonary disease in two large populations. Am J Respir Crit Care Med. 2007;176:167-173.

48. Dahl M, Bowler RP, Juul K, Crapo JD, Levy S, Nordestgaard BG. Superoxide dismutase 3 polymorphism associated with reduced lung function in two large populations. Am J Respir Crit Care Med. 2008;178:906-912.

49. Demeo DL, Hersh CP, Hoffman EA, et al. Genetic determinants of emphysema distribution in the national emphysema treatment trial. Am J Respir Crit Care Med. 2007;176:42-48.

50. Juul K, Tybjaerg-Hansen A, Marklund S, Lange P, Nordestgaard BG. Genetically increased antioxidative protection and decreased chronic obstructive pulmonary disease. Am J Respir Crit Care Med. 2006;173:858-864.

51. Smith CA, Harrison DJ. Association between polymorphism in gene for microsomal epoxide hydrolase and susceptibility to emphysema. Lancet. 1997;350:630-633.

52. Seifart C, Plagens A. Genetics of chronic obstructive pulmonary disease. Int J Chron Obstruct Pulmon Dis. 2007;2:541-550.

53. Silverman EK. Progress in chronic obstructive pulmonary disease genetics. Proc Am Thorac Soc. 2006;3:405-408.

54. Dahl M, Tybjaerg-Hansen A, Vestbo J, Lange P, Nordestgaard BG. Elevated plasma fibrinogen associated with reduced pulmonary function and increased risk of chronic obstructive pulmonary disease. Am J Respir Crit Care Med. 2001;164:1008-1011.

55. Dahl M, Vestbo J, Lange P, Bojesen SE, Tybjaerg-Hansen A, Nordestgaard BG. C-reactive protein as a predictor of prognosis in chronic obstructive pulmonary disease. Am J Respir Crit Care Med. 2007;175:250-255.

56. DiCosmo BF, Geba GP, Picarella D, et al. Airway epithelial cell expression of interleukin-6 in transgenic mice. Uncoupling of airway inflammation and bronchial hyperreactivity. J Clin Invest. 1994;94:2028-2035.

57. Hierholzer C, Kalff JC, Omert L, et al. Interleukin-6 production in hemorrhagic shock is accompanied by neutrophil recruitment and lung injury. Am J Physiol. 1998;275:L611-L621.

58. Johnston RA, Schwartzman IN, Flynt L, Shore SA. Role of interleukin-6 in murine airway responses to ozone. Am J Physiol Lung Cell Mol Physiol. 2005;288:L390-L397.
59. Kuhn C III, Homer RJ, Zhu Z, et al. Airway hyperresponsiveness and airway obstruction in transgenic mice. Morphologic correlates in mice overexpressing interleukin (IL)-11 and IL-6 in the lung. Am J Respir Cell Mol Biol. 2000;22:289-295.

60. Park CS, Chung SW, Ki SY, et al. Increased levels of interleukin-6 are associated with lymphocytosis in bronchoalveolar lavage fluids of idiopathic nonspecific interstitial pneumonia. Am J Respir Crit Care Med. 2000;162:1162-1168.

61. Romani L, Mencacci A, Cenci E, et al. Impaired neutrophil response and CD4+ T helper cell 1 development in interleukin 6-deficient mice infected with Candida albicans. J Exp Med. 1996;183:1345-1355.

62. Romano M, Sironi M, Toniatti C, et al. Role of IL-6 and its soluble receptor in induction of chemokines and leukocyte recruitment. Immunity. 1997;6:315-325.

63. Suwa T, Hogg JC, Klut ME, Hards J, van Eeden SF. Interleukin-6 changes deformability of neutrophils and induces their sequestration in the lung. Am J Respir Crit Care Med. 2001;163:970-976.

64. Xing Z, Braciak T, Jordana M, Croitoru K, Graham FL, Gauldie J. Adenovirus-mediated cytokine gene transfer at tissue sites. Overexpression of IL-6 induces lymphocytic hyperplasia in the lung. J Immunol. 1994;153:4059-4069.

65. Yoshida M, Sakuma J, Hayashi S, et al. A histologically distinctive interstitial pneumonia induced by overexpression of the interleukin 6 , transforming growth factor beta 1, or platelet-derived growth factor B gene. Proc Natl Acad Sci U S A. 1995;92:9570-9574.

66. Luisetti M, Ma S, Iadarola P, et al. Desmosine as a biomarker of elastin degradation in COPD: current status and future directions. Eur Respir J. 2008;32:1146-1157.

67. Kobayashi H, Kanoh S, Motoyoshi K. Serum surfactant protein-A, but not surfactant protein-D or KL-6, can predict preclinical lung damage induced by smoking. Biomarkers. 2008;13:385-392.

68. Sin DD, Man SF, Marciniuk DD, et al. The effects of fluticasone with or without salmeterol on systemic biomarkers of inflammation in chronic obstructive pulmonary disease. Am J Respir Crit Care Med. 2008;177:1207-1214.

69. Ohlmeier S, Vuolanto M, Toljamo T, et al. Proteomics of human lung tissue identifies surfactant protein a as a marker of chronic obstructive pulmonary disease. J Proteome Res. 2008 (in press, available in on-line version).

70. Bhattacharya S, Srisuma S, Demeo DL, et al. Molecular Biomarkers for quantitative and discrete COPD phenotypes. Am J Respir Cell Mol Biol. 2008 (in press, available in on-line version).

71. Larsson K. Inflammatory markers in COPD. Clin Respir J 2008;2:84-87.

72. Snell N, Newbold P. The clinical utility of biomarkers in asthma and COPD. Curr Opin Pharmacol. 2008;8:222-235. 
